\title{
A New Reversible Method of Epiphysiodesis-An Experimental Study in Rabbits
}

\author{
${ }^{1}$ Mahmood Karimi-Mobarakeh, ${ }^{2}$ Reza Malekpour-Afshar, \\ ${ }^{3}$ Nozar Nakhaee, ${ }^{4}$ Om Lahoti and ${ }^{1}$ Mostapha Rahmanian \\ ${ }^{1}$ Department of Orthopaedic Surgery, Shahid Bahonar Medical Centre \\ Kerman Medical Science University, Kerman, Iran \\ ${ }^{2}$ Department of Pathology, Shahid Bahonar Medical Centre \\ Kerman Medical Science University, Kerman, Iran \\ ${ }^{3}$ Department of Community Medicine, Kerman Medical Science University, Kerman, Iran \\ ${ }^{4}$ Department of Orthopaedic Surgery, King's College Hospital (FRCSC), London, UK
}

\begin{abstract}
Lower limb discrepancy and angular deformities are among the most common orthopedic problems in pediatrics. All methods for correction of these deformities are irreversible and the epiphyseal growth plate is arrested. Current study describes a new reversible method of epiphysiodesis. At the first step, we decided to examine angular deformity of the knee. Seven New Zealand white female rabbits with three-week-old age were selected for this study and used a technique of tension band wiring for home epiphysiodesis in the distal of right femur of rabbits. Then comparisons were between operating lower limb as case group and non operated limbs as control group Angular deformity rates had a statistical significant difference between two group $p<0.0001$. No pathological changes appeared in growth plate in two groups grossly and microscopically. Finding of study revealed that the ability of this technique will have potential in treating angular deformities without jeopardizing the future growth potential of the physis.
\end{abstract}

Key words: Epiphysiodesis, Rabbits, Technique

\section{INTRODUCTION}

Leg length discrepancy and angular deformities are common orthopedic problems in children. Several methods like epiphysiodesis, epiphyseal stapling, Phemister technique and percutaneous cauterization or drilling are used to correct these conditions $\left.{ }^{[3,5,8,}, 9\right]$. These methods not only have many complications but also achieve permanent complete closure of the growth plates and arrest $\mathrm{it}^{[4,6,7,11-14]}$.

However orthopedic surgeons like to correct the lower limb discrepancy or angular deformities with the minimum of complication and maximum of efficacy. The aim of this study was to describe a new technique for treatment of lower limb discrepancy or angular deformities that physeal growth plate rate was under control of the surgeon. At the first, we examined this method for temporary cessation of growth in knee angular deformities in Rabbit model.

\section{MATERIAL AND METHODS}

Seven New Zealand white female rabbits threeweek-old age, were selected for this study. All rabbits were following up birthday and everything about animal was recorded on an identification sheet for each. At the first step, we decided to produce angular deformity of the knee thus distal of femur was chosen because of relatively larger and facilitated for surgical manipulation.

Standardized radiography in AP view from both lower limbs of all rabbits in one plate was taken before the first surgical procedure. Then operating place shaved and animals anesthetized by $90 \mathrm{mg} \mathrm{kg}^{-1}$ Ketamine Hydrochloride (Gedeon - Reishter - LTP Hungery) and $10 \mathrm{mg} \mathrm{kg}^{-1}$ Xylazine Hydrochloride 5\% (Bayer Co.-Germany). After prepped and draped under general anesthesia and lateral skin incision, $2-\mathrm{cm}$ in length, knee joint by mini arthrotomy was exposed. A sterilized pin with a small hole at its end entered to epiphysis from lateral to medial. Theoretically, a set which composed of a thin tube with two parallel pins in one side and one screw on the other side can be placed one centimeter above the growth plate by passing the pins lateral to medial of metaphysics These two parts are connected by a piece of number 20 wire by passing through the hole of lower pin and the tunnel of the upper set (Fig. 1). 


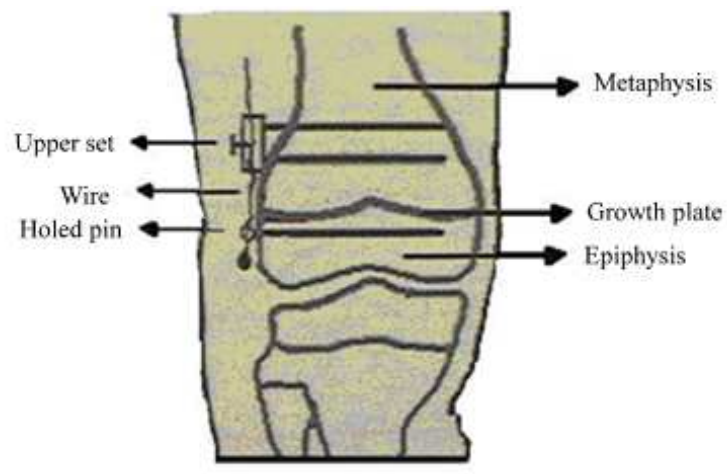

Fig. 1: Schematic Illustration of this New Reversible Epiphysiodesis

In this study, we use a bend pin instead of proximal set and wire turned around it for tightening and opens it for loosening. The wire has a knot in its end near the epiphyseal pin. Two $\mathrm{Cm}$. The extra length of this wire was coated with thigh soft tissue. By tightening of the screw, predictable growth would be stopped and by loosening, growth restarted again.

An incision was sutured by 4/0 nylon. No need for post-operative immobilization. For prevention of post surgical infection $5 \mathrm{mg} \mathrm{kg} \mathrm{kg}^{-1}$ Oxytetracyclin (Darou pakhsh Ltd-IRAN) was injected intramuscularly for 5 days. At two week period in six intervals intermittently screw was making tight and loose by local anesthesia. So that, after first two weeks of tightening, there were two weeks of loosening. At the end of, 4th, 8th and week angle between femur and tibia was measured on the radiograph. In two cases distal pin and wire were embedded in bone. At the end of follow up (after 12 weeks) under general anesthesia, thigh and leg bones with knees were removed and angle of the knee joint in both extremities was measured.

The angles in each step were recorded on identification sheet. Then both lower extremities referred to the pathology department in $10 \%$ formalin solution for evaluation of growth plate microscopic characteristics. In pathology laboratory, the specimens were placed in $10 \%$ Nitric solution for decalcification. A $3 \mathrm{~mm}$ section slice from transcondylar region and the underling physeal plate was prepared. Processing by automated tissue processor-Paraffin embedding and preparation of 5 micrometer slices by microtome- were the next step. Hematoxylin and eosin and Safranin $\mathrm{O}$ stain were used for staining. Each specimen was examined for evidence of physeal closure. After preparing of several sections of physics, the pathologist reported averaged microscopic thickness and microscopic columnar feature, fibrosis, hyalinization, necrosis and inflammation of the growth plate. The thickness of physeal plate was measured with an ocular micrometer in five different regions.

Data were analyzed using SPSS software (version 11.5, SPSS Inc, Chicago<IL). Repeated measures
ANOVA were performed to assess the significance of changes across the three weeks $\left(4^{\text {th }}, 8^{\text {th }}, 12^{\text {th }}\right)$ with $\mathrm{P}$ values less than 0.05 . For paired comparisons between operating and intact knees, paired $t$ test was used $\mathrm{P}<0.01$ were considered significant.

\section{RESULTS}

Rate of angulations was measured at 4, 8 and 12 weeks of study repeatedly and repeated measurement of ANOVA showed a statistical significant difference between them $\mathrm{F}=103.307, \mathrm{P}<0.0001$. In comparison of operated and non-operated group in each week separately significant statistical difference was seen in eighth and twelfth weeks only (Table 1).

Pathology reports were equal to in both groups. In one of the cases and controls respectively there was a loss of columnar arrangement and fibrosis microscopically. A zone of Ranvier was intact in all observed sections. Microscopic thickness in operating group was $0.33 \pm 0.13 \mathrm{~mm}($ mean $\pm \mathrm{SD})$ and in nonoperated group was $0.33 \pm 0.09 \mathrm{~mm}$ that wasn't statistically different $(\mathrm{P}=0.84)$.

\section{DISCUSSION}

Angular deformities around the knee are common in children and various methods have been described to address them, including partial arrest of growth (hemi epiphysiodesis $)^{[3,5,8,9,11,13]}$. Phemister first described a method of epiphysiodesis by bone grafting across the growth plate ${ }^{[4,7,10,11,14]}$. Recent modifications include percutaneous techniques without bone graft ${ }^{[7]}$. They are fairly successful in achieving complete growth arrest. Stapling is known as a reversible method of physeal growth arrest in literature ${ }^{[4,7,11,12]}$. However, the resumption of growth after removal of staples has been unpredictable ${ }^{[12]}$ and it is essential to predict growth inhibition percentage in at least one-year periods. Therefore, suitable age for this operation is near skeletal maturity ${ }^{[2,3,7,14]}$.

Ross and Zions compared three methods of inhibiting physical growth in a rabbit model. They concluded that the growth inhibition rate is higher with Phemister technique $(8.8 \%)$ than stapling $(8 \%)$ and percutaneous technique $(6.2 \%)^{[11]}$. These investigators did not comment on resumption of growth after any of these procedures. Stapling is often credited with least damage to the growth plate thus assuring growth of the physician after removal. Blount and Clarke, in their series of thirteen children did not report a single case of growth failure ${ }^{[12]}$. However, others did not reproduce this, either in humans or animals. Failure of metal staple and occasional arrests of whole physics when stapling was carried out for hemi epiphysiodesis were also reported ${ }^{[1-3,5,9,13,14]}$. In spite of these drawbacks, stapling continues to be popular. 
Table 1: Mean Difference of Angulations in Different Time

\begin{tabular}{lccc}
\hline $\mathrm{P}$ value & Standard deviation & Mean difference between operated and non-operated & Time \\
\hline $\mathrm{T}=2.117, \mathrm{P}=0.08$ & 5.2 & 4.5 & After 4 weeks \\
$\mathrm{T}=2.241, \mathrm{P}=0.001$ & 6.1 & 18.2 & After 8 weeks \\
$\mathrm{T}=2.582, \mathrm{P}=0.001$ & 9.5 & 29.7 & After 12 weeks \\
\hline
\end{tabular}

In our study, we describe a method, which achieves growth inhibition by a tension band effect on the side of surgery. It is effective in achieving predictable growth inhibition on the side of surgery as is evident from progressive angular deformity.

Histopathology studies consistently demonstrated viable, healthy physical plate except in one case where loss of columnar arrangement was noted.

We conclude that the technique described in this study promises to be least damaging to the physis in a rabbit model and because the cause for growth inhibition is a wire anchored securely in metaphysics and epiphysis there is no chance for failure. Furthermore, it can be used in early age and put in place for a long time in the loose position after full correction and if necessary tightens it again. Further studies are planned to assess its efficacy in higher mammals (sheep) and in clinical practice.

\section{ACKNOWLEDGEMENTS}

The authors thank Kerman University Research Centre of Medical Sciences to grant support of this study.

\section{REFERENCES}

1 Anderson, M., W.T. Green and M.B. Messner, 1963. Growth and predictions of growth in lower extremities. J Bone Joint Surg [Am], 45: 10-15.

2. Anderson, M., M.B. Messner and W.T. Green, 1964. Distribution of lengths of the normal femur and tibia in children from one to eighteen years of age. J Bone Joint Surg [Am], 46: 1199-206.

3. Beaty, J.H., 2003. Congenital anomalies of lower limb. In: Canale ST. Campbell's operative orthopedics, $10^{\text {th }}$ Ed, Mosby, Philadelphia, pp: 1042-51.

4. Green, W.T. and M. Anderson, 1957. Epiphyseal arrest for the correction of discrepancies in length of the lower extremities. J Bone Joint Surg. [Am], 39: 853-72.
5. Herring, J.A., 2002. Tachdjian's pediatric orthopedics. $3^{\text {rd }}$ Ed, WB Saunders, Philadelphia, pp: 839-91, 1039-1119.

6. Kaweblum, M., M.C. Aguilar and E. Blancas et al., 1994. Histological and radiographic determination of the age of physeal closure of the distal femur, proximal tibia and proximal fibula of the New Zealand white rabbit. J Orthopaed. Res., 12: 747-9.

7. Ogilive, J.W., 1986. Epiphysiodesis: evaluation of a new technique. J Pediatr Orthop., 6: 147-9.

8. Peterson, H.A., 1996. Physical and apophyseal injuries. In: Rockwood, C.A., K.E. Wilkins, J.H. Beaty (Eds). Fractures in children, $4^{\text {th }}$ Ed., Lippincott-Raven, Philadelphia, pp: 103-167.

9. Peterson, H.A., 1990. Partial growth plate arrest and its treatment. In: Morrissy, R.T. and S.L. Weinstein (Eds). Lovell and Winter's pediatric orthopedics. $\quad 3^{\text {rd }}$ Edn, Lippincottt-Raven, Philadelphia, pp: 1071-89.

10. Phemister, D., 1933. Operative arrestment of longitudinal growth in the treatment of deformities. J Bone Joint Surg [Am], 15: 1-15.

11. Ross, T.K. and L.E. Zionts, 1997. Comparison of different methods used to inhibit physical growth in a rabbit model. Clin Orthop, 340: 236-43.

12. Siffert, R.S., 1956. The effect of staples and longitudinal wires on epiphyseal growth. An experimental study. J Bone Joint Surg [Am], 38: 1077-88.

13. Theologis, T.N., 2002. Musculoskeletal injuries in children. In $1^{\text {st }}$ Edn. Oxford Textbook of Orthopaedics and Trauma. Oxford University Press, 3: 2629-2642.

14. Thompson, G.H., 2001. Angular deformities of the lower extremities in children. In $3^{\text {rd }} \mathrm{Edn}$. Chapman's orthopedic surgery. Lippincot William and Wilkins. Philadelphia, pp: 4304-4315. 